\title{
NUTRIENT LIMITATION AND UPTAKE RATES IN STREAMS AND RIVERS OF THE GREATER YELLOWSTONE AREA
}

\author{
JENNIFER L. TANK $\uparrow$ ALEXANDER J. REISINGER $\uparrow$ UNIVERSITY OF NOTRE DAME
}

\begin{abstract}
$\uparrow$ ABSTRACT
Nutrient pollution of aquatic ecosystems is a growing concern as the influence of human activities continues to increase on the landscape. Headwater streams have long been shown to process nutrients via the biofilm community growing on the bottom of streams. The growth and activity of these biofilms is often limited by the availability of nitrogen $(\mathrm{N})$, phosphorus $(\mathrm{P})$, or co-limited by both $\mathrm{N}$ and $\mathrm{P}$. Although small stream nutrient dynamics are relatively well understood, comparatively little is known about larger, non-wadeable rivers. Biofilms on the river bottom are likely still nutrient limited, but there becomes an increased potential for light limitation as rivers increase in depth. In addition to biofilms on the bottom of rivers, free-living microbial communities suspended in the water column also occur in rivers and process nutrients - a component of nutrient processing largely ignored in streams. In summer 2013 we worked in streams and rivers of the Greater Yellowstone Area (GYA) to establish the nutrient limitation status of minimally-impacted rivers, as well as the role of the water column in processing nutrients as streams increase in size. For both the nutrient limitation and water column uptake studies, we are using the GYA sites in addition to systems from other regions of the US to establish what controls the various aspects of nutrient dynamics in rivers. Our results from the GYA, in addition to Midwest and Southwest US rivers, will provide water quality managers with new strategies for improving water quality downstream, and clarify mechanisms controlling nutrient retention in rivers.
\end{abstract}

\section{$\uparrow \quad$ INTRODUCTION}

Biofilms made up of algae, bacteria, and fungi colonize virtually every surface of stream and river bottoms (i.e., benthos). This bioreactive assemblage drives numerous ecosystem functions, including primary production and nutrient retention (Cummins 1974, Peterson et al. 2001). These biofilms, and their ability to perform these ecosystem functions, may be limited by the availability of nitrogen $(\mathrm{N})$, phosphorus (P), or co-limited by both $\mathrm{N}$ and $\mathrm{P}$ (Pringle et al. 1986, Tank and Dodds 2003, Johnson et al. 2009). Although N or P may limit benthic biofilms, colimitation by both $\mathrm{N}$ and $\mathrm{P}$ is the most common in freshwater ecosystems (Francoeur 2001, Elser et al. 2007, Harpole et al. 2011). The nutrient limitation status of biofilms can be used as a metric to characterize stream and river health (Bunn et al. 1999, Johnson et al. 2009), and is an important mechanism regulating nutrient retention in stream networks (Hill et al. 2010).

Nutrient limitation of a system strongly influences the ability of stream networks to retain nutrients exported from the terrestrial landscape. Streams that are more nutrient limited are more likely to be 'retentive', thus reducing nutrient export to sensitive downstream ecosystems. Nutrients retained within a stream network may alleviate eutrophication in downstream ecosystems (Alexander et al. 2000). Nutrient processing by benthic biofilms in headwater streams, and the nutrient limitation of these biofilms has been the primary focus of stream ecology due to the predominate role of benthic biofilms and headwater streams at regional scales (Peterson et al. 2001, Alexander et al. 2007).

In contrast to headwater streams, which make up the majority of stream miles throughout a stream network (Alexander et al. 2007), ecosystem function in larger rivers may be driven by a free-living, suspended biological community rather than the biofilms attached to the stream bed. This shift from the benthos to the water column is driven by shifts in the physical environment of a stream as it increases in size and becomes a river (Vannote et al. 1980). As streams increase in size, they become wider and deeper, increasing the light reaching the water's surface (due 
to decreased canopy cover) but reducing the light reaching the benthos (due to deeper, and potentially more turbid, waters). This physical change in the river environment is predicted to shift the biological community to a more lake-like, pelagic community (Vannote et al. 1980). If the biological community indeed moves to the water-column, pelagic processes should also become more important for nutrient retention. Unfortunately, there have been very few studies performed in non-wadeable rivers (Tank et al. 2008); ecologists have primarily focused on small streams, or very large rivers (e.g., the Hudson River (Caraco et al. 2006)). The lack of empirical research in moderately sized, non-wadeable rivers has led to the false dichotomy of either benthic or pelagic processes dominating flowing waters. In reality, there is likely a transition zone in which rivers of a certain size exhibit both benthic and pelagic ecosystem processes.

For the past few decades ecosystem ecology of flowing waters has focused primarily on small, headwater streams (Mulholland et al. 1985, Peterson et al. 2001, Hall et al. 2009). This is reflected by a preponderance of nutrient uptake studies occurring in small streams (Ensign and Doyle 2006, Tank et al. 2008), and is likely due to a combination of the methodological challenges of working in larger river systems (Mulholland and Webster 2010) coupled with the high value, and extreme sensitivity of headwater streams (Peterson et al. 2001). While incredibly valuable, this focus on headwater streams has led to a knowledge gap surrounding non-wadeable rivers. Indeed, an improved understanding of riverine nutrient cycling should be a priority for stream ecologists (Mulholland and Webster 2010).

To achieve a better understanding of riverine nutrient dynamics, and as part of a larger, NSF-funded project, we have quantified riverine uptake of ammonium $\left(\mathrm{NH}_{4}{ }^{+}\right)$, nitrate $\left(\mathrm{NO}_{3}{ }^{-}\right)$, and phosphorus $(\mathrm{P})$ in 15 rivers across the United States. In 2010, we studied five of these rivers located in or near the Greater Yellowstone Area (GYA) (Snake, Buffalo Fork, Henrys Fork, Green at Seedskadee, and Salmon). During this work we found that rivers in the GYA are biologically active, and indeed process nitrogen at rates comparable to, or even higher than, rates found in small streams located within Grand Teton National Park (GTNP) (Hall and Tank 2003, Tank et al. 2008, Tank et al. in prep). This result reinforced the idea that rivers deserve increased scientific attention and led to the research we performed in 2013 .
Although our work in 2010 quantified nutrient uptake rates in these rivers, the processes driving uptake were treated as a black box. In 2013, we set out to measure some potential drivers of nutrient uptake in rivers of the GYA and to identify where the transition from benthic to pelagic dominated rivers occurs. Data collected in 2013 will be combined with studies from the Southwest and Midwest US to describe nutrient processing in the pelagic zone, and nutrient limitation in the benthic zone, in a wide variety of river systems.

\section{$\uparrow \quad$ STUDY AREA}

Our 2013 work was conducted in five rivers throughout the GYA as well as three streams in GTNP. We determined benthic nutrient limitation in four of the five rivers we studied in 2010. We substituted the Teton River near Driggs, ID for the Salmon River because (1): traveling to the Salmon River was financially and logistically unfeasible, and (2) we contracted with the Idaho Department of Environmental Quality (ID-DEQ) to study nutrient limitation in the Teton River near the site of a new waste-water treatment plant. In addition to the nonwadeable rivers where we measured nutrient limitation, we measured pelagic nutrient uptake in Ditch Creek near the Teton Science School, lower Spread Creek approximately $1 \mathrm{~km}$ upstream of its confluence with the Snake River, and Pacific Creek where it flows under US-287.

\section{$\uparrow \quad$ METHODS}

\section{Pelagic nutrient uptake}

We measured pelagic nutrient processing using the in situ chamber incubation approach of Reisinger et al. (in prep). Briefly, we filled $3 \mathrm{~L}$ clear polycarbonate chambers $(n=15)$ with depth-integrated river water. We then amended each chamber with one of three solutes $\left(\mathrm{NH}_{4}{ }^{+}, \mathrm{NO}_{3}{ }^{-}\right.$, or $\left.\mathrm{SRP}\right)$ to a target concentration of $30 \mu \mathrm{g} \mathrm{L}^{-1}$ above background. After this amendment, we homogenized each chamber by inverting three times. We immediately collected an initial water chemistry sample to represent time zero within each chamber. We then suspended chambers at the surface of the water column to insure ambient temperature conditions and provide maximum ambient light availability over the course of the $4 \mathrm{~h}$ incubation (Figure 1). Starting with time zero, we collected a water sample from each chamber every hour over the course of the incubation, amounting to a total of 5 water chemistry samples from each chamber. 


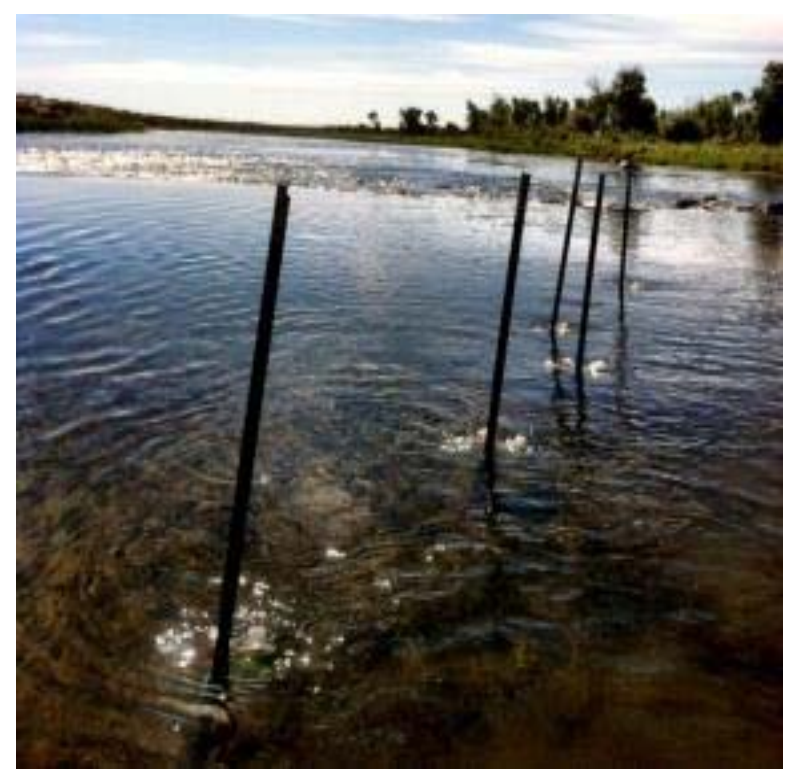

Figure 1. An example of a pelagic nutrient uptake incubation experiment performed in the Green River at Seedskadee National Wildlife Refuge.

We collected water chemistry samples throughout all incubations by removing $60 \mathrm{~mL}$ of water from the chamber, filtering $20 \mathrm{~mL}$ of the sample through a $0.2 \mu \mathrm{m}$ SUPOR filter (Pall Corporation, Port Washington, NY, USA) into a sterile $50 \mathrm{~mL}$ centrifuge tube (VWR, Radnor, PA, USA) as a rinse. After rinsing, we filtered the remaining $40 \mathrm{~mL}$ of sample into the tube and stored samples on ice until return to the laboratory, where we stored samples frozen until analysis. We quantified dissolved $\mathrm{NH}_{4}{ }^{+}$using the phenol-hypochlorite method (Solorzano 1969), $\mathrm{NO}_{3}^{-}$ using the cadmium reduction method (APHA 1995), and $\mathrm{P}$ using the ascorbic acid method (Murphy and Riley 1962) on a Lachat Flow Injection Autoanalyzer (Lachat Instruments, Loveland, CO, USA). To quantify nutrient uptake, we calculated the first order decay rate of nutrients over time $\left(\mathrm{k} ; \mathrm{h}^{-1}\right)$ and then converted this decay rate to volumetric uptake $(\mathrm{U} ; \mathrm{mg}$ $\mathrm{m}^{-3} \mathrm{~h}^{-1}$ ) by multiplying by background concentration.

\section{Benthic nutrient limitation}

We quantified benthic nutrient limitation using nutrient diffusing substrata (NDS). We constructed NDS using $30 \mathrm{~mL}$ polycon cups filled with a $2 \%$ agar solution amended with $0.5 \mathrm{M} \mathrm{NH}_{4} \mathrm{Cl}$ ( $\mathrm{NH}_{4}{ }^{+}$treatment), $0.5 \mathrm{M} \mathrm{NaNO}_{3}\left(\mathrm{NO}_{3}{ }^{-}\right.$treatment), 0.5 $\mathrm{M} \mathrm{KH}_{2} \mathrm{PO}_{4}\left(\mathrm{PO}_{4}{ }^{3-}\right.$ treatment $), 0.5 \mathrm{M}$ of both $\mathrm{NH}_{4} \mathrm{Cl}$ and $\mathrm{KH}_{2} \mathrm{PO}_{4}\left(\mathrm{NH}_{4}{ }^{+}\right.$and $\mathrm{PO}_{4}{ }^{3-}$ treatment), $0.5 \mathrm{M}$ of both $\mathrm{NaNO}_{3}$ and $\mathrm{KH}_{2} \mathrm{PO}_{4}\left(\mathrm{NO}_{3}{ }^{-}\right.$and $\mathrm{PO}_{4}{ }^{3-}$ treatment $)$, or no amendment as a control $(\mathrm{C}$ treatment; Tank et al. 2006). We then topped NDS with either inorganic fritted glass disks or organic cellulose sponge cloth (Johnson et al. 2009) for a total of five replicates for each treatment and substratum type. The use of both inorganic and organic substrata allowed us to examine nutrient limitation of both autotrophic and heterotrophic biofilm components (Tank and Dodds 2003, Johnson et al. 2009). Once the agar had solidified and disks were placed on top, we attached the cups to PVC L-bars using cable ties. We attached the L-bars to a cinder block at each site, which we then placed in the main channel as near to the main current as we could reach with the NDS remaining upright (Figure 2). Based upon NDS deployment in other rivers, we elevated the L-bar on cinder blocks in order to minimize the potential for burial of NDS by fine sediments.

After incubating for 14 days, we retrieved NDS from the river. Substrata were placed in $50 \mathrm{~mL}$ centrifuge tubes. We immediately performed metabolism incubations on the substrata within these centrifuge tubes. First, we measured the initial temperature and dissolved oxygen (DO; as both $\mathrm{mg} \mathrm{O}_{2}$ $\mathrm{L}^{-1}$ and \% saturation) of a $20 \mathrm{~L}$ bucket of unfiltered river water (to serve as the initial DO for the incubation). We then filled the tubes containing NDS substrata with unfiltered stream water in the bucket, capping the tubes underwater to insure no air bubbles were present. We also filled three centrifuge tubes with river water only to serve as a water-column control. To measure ecosystem respiration (ER), we covered the tubes with dark sleeves, made of aluminum foil and duct tape shaped to tightly cover the centrifuge tubes. We performed ER incubations in the river at ambient temperature for $2 \mathrm{~h}$. After the incubation period was over, we measured the final temperature and $\mathrm{DO}$ in each tube. The difference between initial and final DO provides ER $\left(\mathrm{mg} \mathrm{O}_{2} \mathrm{~h}^{-1}\right)$, which was then scaled areally based upon the known surface area of the substrata.

Following ER incubations, we emptied the water from all of the tubes, and refilled them from a bucket of fresh river water. Following the same protocol as the ER incubations, we measured net primary production (NPP) as the change in DO over a $1.5 \mathrm{~h}$ incubation with no sleeves covering the tubes. The light incubations provide net primary production (NPP) under ambient light and temperature. We calculated gross primary production (GPP) as:

$$
\mathrm{GPP}=\mathrm{NPP}+\operatorname{abs}(\mathrm{ER})
$$

where GPP is gross primary production, and abs (ER) is the absolute value of ecosystem respiration (traditionally expressed as a negative due to the 
decrease in oxygen caused by respiration). All metabolic variables are expressed as $\mu \mathrm{g} \mathrm{O}_{2} \mathrm{~cm}^{-2} \mathrm{~h}^{-1}$.

Upon completion of light incubations, we removed NDS substrata from the incubation tubes, wrapped them in aluminum foil, and stored them frozen until they were returned to the lab where we quantified algal biomass on each substratum as chlorophyll $a(\operatorname{chl} a)$. We analyzed substrata for chl $a$ using the cold methanol fluorometric method (Wetzel and Likens 2000), but chl $a$ results are not included in this report.

\section{Statistical analysis}

To quantify the nutrient limitation status of autotrophic and heterotrophic biofilm productivity, we ran two-way analysis of variance (ANOVA) on GPP and $\mathrm{R}$ of both inorganic and organic disks using the metabolic rate as the response variable and the presence of $\mathrm{N}$ and/or P in the NDS as the factors (Tank and Dodds 2003). As we had two different forms of $\mathrm{N}$

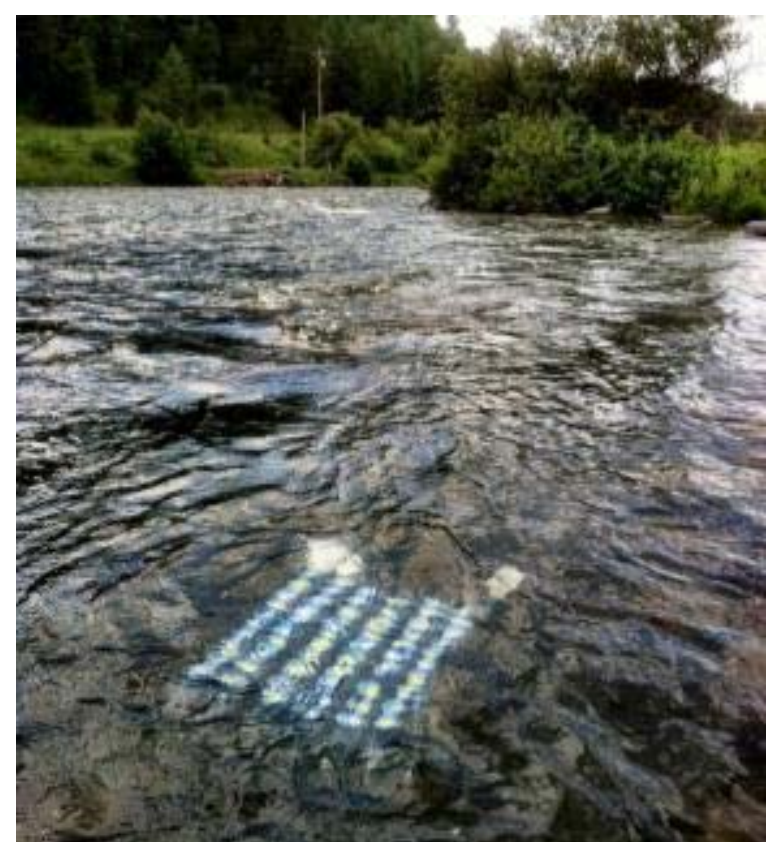

Figure 2. Nutrient diffusing substrata were deployed in five rivers throughout the GYA.

added to different NDS, we ran ANOVAs using $\mathrm{NH}_{4}{ }^{+}$ and $\mathrm{NO}_{3}{ }^{-}$amended NDS separately to determine if $\mathrm{N}$ form added to NDS altered limitation patterns. To establish the controls of pelagic nutrient processing in streams of different size, we ran a simple linear regression with nutrient uptake of each solute as our response variable and different potential environmental factors as our predictor variables. We initially ran regressions using only GYA sites, but realized that we did not have enough variation and/or statistical power to find significant patterns, and therefore included all 15 study sites we have for our study of pelagic nutrient uptake across streams of different sizes. Therefore, for these regressions we have 15 different study sites: the three streams analyzed in 2013, pelagic nutrient uptake measured in the Snake and Buffalo Fork in 2010, and 5 sites each in moderately and highly human influenced Midwest US watersheds. For nutrient limitation, only results from the 2013 work will be presented in this report, but these results will be combined with work from the Midwest (spanning 2011 - 2014) and Southwest (2012) resulting in three separate manuscripts: (1) Pelagic nutrient processing along a stream size gradient (in prep to be submitted to Biogeochemistry by Summer 2014), (2) Pelagic nutrient uptake in 15 rivers spanning a nutrient and turbidity gradient (in prep to be submitted to Ecology by Fall 2014), and (3) Spatial and temporal variation of benthic nutrient limitation in rivers (still collecting data from Midwest rivers).

\section{$\uparrow \quad$ PRELIMINARY RESULTS}

\section{Nutrient limitation}

Benthic biofilms in the five study rivers within the GYA all exhibited some sort of nutrient limitation, regardless of functional response. When analyzing $\mathrm{NH}_{4}{ }^{+}$as the $\mathrm{N}$ treatment, GPP of autotrophic biofilms was $\mathrm{N}$ limited at three rivers, $\mathrm{P}$ limited at one river, and co-limited by $\mathrm{N}$ and $\mathrm{P}$ at one river (Figure $3 \mathrm{~A}$ ). In contrast to $\mathrm{NH}_{4}{ }^{+}$, when using $\mathrm{NO}_{3}{ }^{-}$as the $\mathrm{N}$ treatment, biofilm GPP was co-limited by $\mathrm{N}$ and $\mathrm{P}$ at four rivers, and $\mathrm{N}$ limited at one river (Figure $3 \mathrm{~B}$ ). Ecosystem respiration of heterotrophic biofilms was primarily $\mathrm{N}$ limited at the majority of rivers, regardless of which $\mathrm{N}$ treatment we analyzed. First, when using $\mathrm{NH}_{4}{ }^{+}$as the $\mathrm{N}$ treatment, ER was $\mathrm{N}$ limited in four of the five rivers and co-limited by $\mathrm{N}$ and $\mathrm{P}$ at one river (Figure $3 \mathrm{C}$ ). When using $\mathrm{NO}_{3}^{-}$as the $\mathrm{N}$ treatment, ER was $\mathrm{N}$ limited at all five rivers studied in the GYA (Figure 3D).

These results are consistent with what we would expect from rivers in the GYA. The relative lack of human development in the region, coupled with the high $\mathrm{P}$ availability due to the underlying geology, makes the prevalence of $\mathrm{N}$ limitation unsurprising. The one site where we found any implication of solely P limitation was the Teton River near Driggs, ID. We were asked to study this river by the ID-DEQ as a new wastewater treatment plant is being installed to serve the city of Driggs and there is 
already increased human development in this region relative to the other rivers in this study, so it makes sense that this river might exhibit different nutrient limitation patterns from the other four rivers.

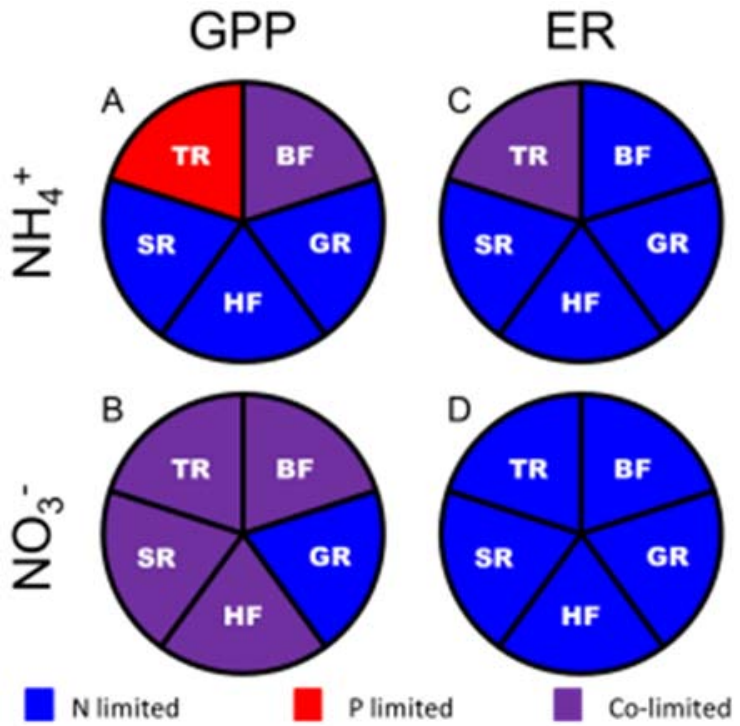

Figure 3. Nutrient limitation status of biofilm gross primary production $(\mathrm{A}, \mathrm{B})$ and ecosystem respiration $(\mathrm{C}, \mathrm{D})$ using either $\mathrm{NH}_{4}{ }^{+}(\mathrm{A}, \mathrm{C})$ or $\mathrm{NO}_{3}^{-}(\mathrm{B}, \mathrm{D})$ in five rivers in the GYA. Each lie of the pie represents one river: $\mathrm{BF}=$ Buffalo Fork, $\mathrm{GR}=$ Green River, $\mathrm{HF}=$ Henrys Fork, $\mathrm{SR}=$ Snake River, $\mathrm{TR}=$ Teton River. Each color represents a different nutrient limitation classification: blue $=\mathrm{N}$ limited, $\mathrm{red}=\mathrm{P}$ limited, purple $=$ co-limited by $\mathrm{N}$ and $\mathrm{P}$.

\section{Water column nutrient uptake}

We were able to measure nutrient uptake in the water column at all three streams we worked in during summer 2013. Unlike human impacted systems we have worked in previously, volumetric uptake of $\mathrm{P}$ was higher than either $\mathrm{NH}_{4}^{+}$or $\mathrm{NO}_{3}^{-}$. Volumetric $\mathrm{P}$ uptake ranged from $0.62 \mathrm{mg}$ to $0.81 \mathrm{mg} \mathrm{m}^{-3} \mathrm{~h}^{-1}$. Ammonium uptake ranged from 0.15 to $0.31 \mathrm{mg} \mathrm{m}^{-3}$ $\mathrm{h}^{-1}$, which was generally higher than nitrate uptake, which ranged from 0.01 to $0.17 \mathrm{mg} \mathrm{m}^{-3} \mathrm{~h}^{-1}$. Although we only have a sample size of three streams from Summer 2013, it appears that P uptake decreased with background $\mathrm{P}$ concentration while $\mathrm{NH}_{4}^{+}$uptake appears to increase with background $\mathrm{NH}_{4}^{+}$ concentration. These opposing trends could be suggesting that at lower $\mathrm{P}$ concentrations, water column biota assimilate whatever $\mathrm{P}$ is available, whereas higher $\mathrm{P}$ concentrations alleviates the need to assimilate $\mathrm{P}$ at high rates. This could be an example of luxury $\mathrm{P}$ uptake, which has been seen previously in lake phytoplankton (Wetzel 1992), and is implicated in water column nutrient uptake in 15 rivers across the United States (Reisinger et al. in prep), but has not been seen previously in streams.
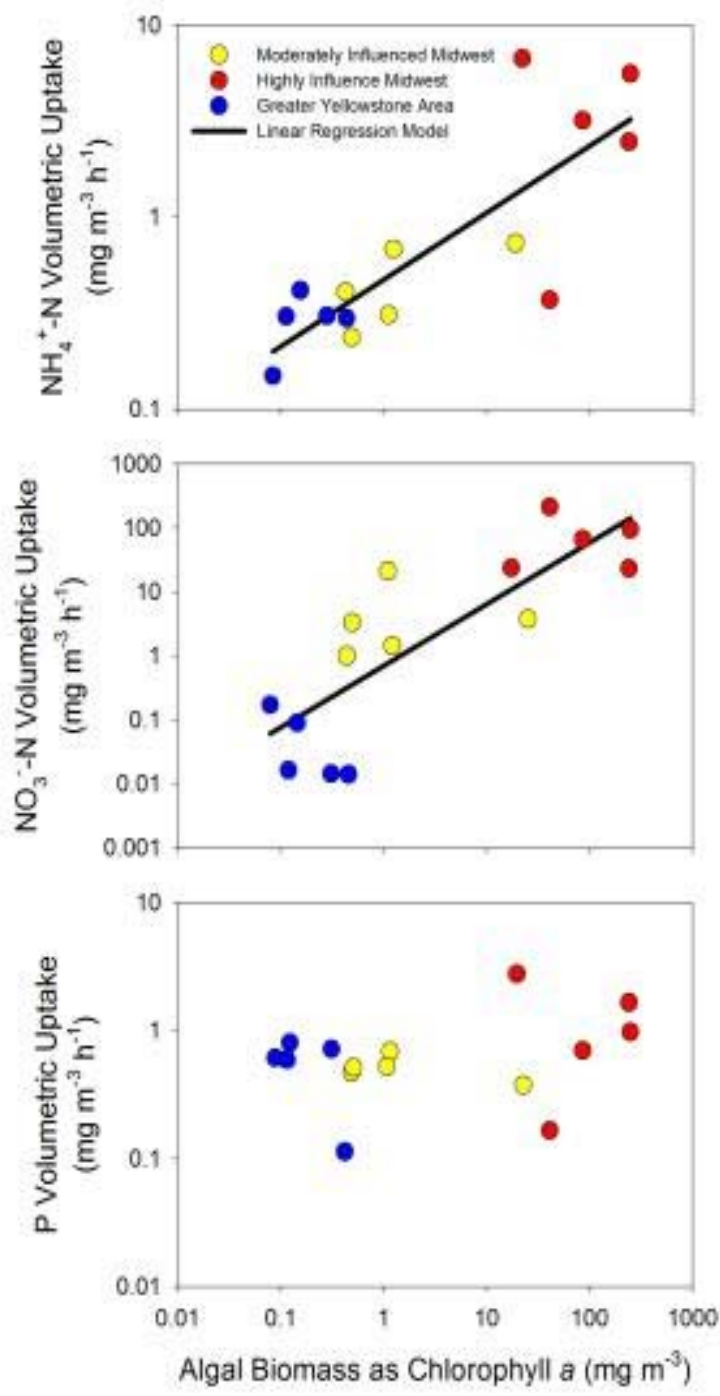

Figure 4. Volumetric uptake of $\mathrm{NH}_{4}{ }^{+}$and $\mathrm{NO}_{3}^{-}$ increased with algal biomass, whereas $\mathrm{P}$ uptake did not respond to algal biomass. Different colors represent different watersheds (blue $=$ GYA, yellow $=$ moderately influenced, and red=highly influenced by human activities).

As part of a larger project based upon the hypothesis that pelagic uptake increases with stream size, we combined volumetric uptake measured in 3 streams in summer 2013 with measurements taken in summer 2010 at the Buffalo Fork and Snake. We did 
not find any correlation between stream size (using watershed area as the stream size metric) and volumetric uptake of $\mathrm{NH}_{4}^{+}, \mathrm{NO}_{3}^{-}$, or $\mathrm{P}$. This was similar to the lack of any correlation between volumetric uptake and stream size in two Midwest watersheds (data not shown). We then attempted to find environmental factors that controlled volumetric uptake in GYA streams and rivers. However, the amount of variability in the environmental factors that we predicted would control pelagic uptake in the GYA was very low. Because of this low variability, we were unable to establish the controls on pelagic uptake in GYA streams and rivers. However, when we combined our measurements of pelagic uptake from GYA systems with measurements from both a moderately influenced, and a highly influenced Midwest watershed, after transforming data to meet assumptions of normality, we find that uptake of $\mathrm{NH}_{4}^{+}$ and $\mathrm{NO}_{3}{ }^{-}$is positively correlated with chlorophyll $a$ ( $\mathrm{R}^{2}=0.75$ and 0.68 , respectively, $\mathrm{p}<0.01$ for both), whereas $\mathrm{P}$ uptake is not (Figure 4).

\section{$\uparrow \quad$ MANAGEMENT IMPLICATIONS}

Our research in the GYA had two primary objectives: (1) establish the nutrient limitation status of riverine biofilms in minimally impacted rivers; and (2) quantify pelagic nutrient uptake in headwater streams to inform a larger study on the response of pelagic nutrient processing to increasing stream size. The high degree of $\mathrm{N}$ limitation of riverine biofilms found in these rivers suggests that biofilms in rivers of this size are processing nutrients in similar fashion to those in headwater streams. This is in contrast to results of a study in rivers in the Southwest United States which also had low nutrients, but had high loads of suspended sediment - these 'muddy' rivers were typically not nutrient limited and instead were likely limited by light (Reisinger et al. unpublished data). This implies that if light availability were increased in human-influenced systems via reducing erosion and suspended sediment loads, nutrient retention should increase. In addition to the nutrient limitation results, our pelagic nutrient uptake results show that even in small, headwater streams, nutrients are processed in the water column. This is counter to previous research and provides an additional nutrient removal mechanism to be optimized by managers.

Although our results from summer 2013 only provide a snapshot of the big picture, serving as a 'minimally influenced' end point for our studies, we do find that rivers appear capable of processing nutrients in ways previously ignored. Incorporating the results from the GYA into the bigger picture in the coming years will reveal processes and controls on the multitude of nutrient processing mechanisms in rivers, providing water quality managers with new strategies for improving downstream water quality.

\section{ACKNOWLEDGEMENTS}

In addition to support from the UW-NPS Research Station, this work has been supported by funding from the National Science Foundation, the IDDEQ, and a Graduate Student Endowment Award from the Society for Freshwater Science provided to AJ Reisinger. Access to sites was graciously provided by GTNP, with particular support from Sue ConsoloMurphy, as well as the Seedskadee National Wildlife Refuge, and the ID-DEQ. The design and logistics of this research has been improved by Dr. Emma J. RosiMarshall of the Cary Institute of Ecosystem Studies, Dr. Michelle A. Baker of Utah State University, and Dr. Robert O. Hall of the University of Wyoming. Dr. Hall was also incredibly helpful in terms of helping with site selection.

\section{LITERATURE CITED}

Alexander, R. B., E. W. Boyer, R. A. Smith, G. E. Schwarz, and R. B. Moore. 2007. The role of headwater streams in downstream water quality. JAWRA Journal of the American Water Resources Association 43: 41-59.

Alexander, R. B., R. A. Smith, and G. E. Schwarz. 2000. Effect of stream channel size on the delivery of nitrogen to the Gulf of Mexico. Nature 403: 758-761.

American Public Health Association (APHA). 1995. Standard Methods for the Examination of Water and Wastewater. American Public Health Association, American Water Works association, Water Environment Federation, Washington.

Bunn, S. E., P. M. Davies, and T. D. Mosisch. 1999. Ecosystem measures of river health and their response to riparian and catchment degradation. Freshwater Biology 41:333345.

Caraco, N. F., J. J. Cole, and D. L. Strayer. 2006. Top down control from the bottom: Regulation of eutrophication in a large river by benthic grazing. Limnology and Oceanography 51: 664-670.

Cotner, J. B., and R. G. Wetzel. 1992. Uptake of dissolved inorganic and organic phosphorus compounds by phytoplankton and bacterioplankton. Limnology and Oceanography 37: 232-243. 
Cummins, K. W. 1974. Structure and function of stream ecosystems. BioScience 24: 631-641.

Elser, J. J., M. E. S. Bracken, E. E. Cleland, D. S. Gruner, W. S. Harpole, H. Hillebrand, J. T. Ngai, E. W. Seabloom, J. B. Shurin, and J. E. Smith. 2007. Global analysis of nitrogen and phosphorus limitation of primary producers in freshwater, marine and terrestrial ecosystems. Ecology Letters 10: 1135-1142.

Ensign, S. H., and M. W. Doyle. 2006. Nutrient spiraling in streams and river networks. Journal of Geophysical Research 111: G404009.

Francoeur, S. N. 2001. Meta-analysis of lotic nutrient amendment experiments: Detecting and quantifying subtle responses. Journal of the North American Benthological Society 20: 358-368.

Hall R. O., and Tank J. L. 2003. Ecosystem metabolism controls nitrogen uptake in streams in Grand Teton National Park, Wyoming. Limnology and Oceanography 48:1120-1128.

Hall, R. O., J. L. Tank, D. J. Sobota, P. J. Mulholland, J. M. O’Brian, W. K. Dodds, J. R. Webster, H, M. Valett, G. C. Poole, B. J. Peterson, J. L. Meyer, W. H. McDowell, S. L. Johnson, S. K. Hamilton, N. B. Grimm, S. V. Gregory, C. M. Dahm, L. W., Cooper, L. R., Ashkenas, S. M. Thomas, R. W. Sheibley, J. D. Potter, B. R. Niederlehner, L. T. Johnson, A. M. Helton, C. M. Crenshaw, A. J. Burgin, M. J. Burnot, J. J. Beaulieu, and C. P. Arango. 2009. Nitrate removal in stream ecosystems measured by $15 \mathrm{~N}$ addition experiments: Total uptake. Limnology and Oceanography 54: 653-665.

Harpole, W. S., J. T. Ngai, E. E. Cleland, E. W. Seabloom, E. T. Borer, M. E. S. Bracken, J. J. Elser, D. S. Gruner, H. Hillebrand, J. B. Shurin, and J. E. Smith. 2011. Nutrient colimitation of primary producer communities. Ecology Letters 14: 852-862.

Hill, B. H., F. H. McCormick, B. C. Harvey, S. L. Johnson, M. L. Warren, and C. M. Elonen. 2010. Microbial enzyme activity, nutrient uptake and nutrient limitation in forested streams. Freshwater Biology 55: 1005-1019.

Johnson, L. T., J. L. Tank, and W. K. Dodds. 2009. The influence of land use on stream biofilm nutrient limitation across eight North American ecoregions. Canadian Journal of Fisheries and Aquatic Sciences 66:10811094.
Mulholland, P. J., J. D. Newbold, J. W. Elwood, L. A. Ferren, and J. R. Webster. 1985. Phosphorus spiraling in a woodland stream: Seasonal variations. Ecology 66: 1012-1023.

Mulholland, P. J., and J. R. Webster. 2010. Nutrient dynamics in streams and the role of $\mathrm{J}$ NABS." Journal of the North American Benthological Society 29: 100-117.

Murphy, J., and J.P. Riley. 1962. A modified single solution method for the determination of phosphate in natural waters. Analytica chimica acta 27: 31-36.

Peterson, B. J., W. M. Wollheim, P. J. Mulholland, J. R. Webster, J. L. Meyer, J. L. Tank, E. Marti, W. B. Bowden, H. M. Valett, A. E. Hershey, W. H. McDowell, W. K. Dodds, S. K. Hamilton, S. Gregory, and D. D. Morrall. 2001. Control of nitrogen export from watersheds by headwater streams. Science 292: 86-90.

Pringle, C. M., P. Paaby-Hansen, P. D. Vaux, and C. R. Goldman. 1986. In situ nutrient assays of periphyton growth in a lowland Costa Rican stream. Hydrobiologia 134: 207-213.

Solorzano, L. 1969. Determination of ammonia in natural waters by the phenolhypochlorite method. Limnology and Oceanography 14: 799-801.

Tank, J. L., M. J. Bernot, and E. J. Rosi-Marshall. 2006. Nitrogen limitation and uptake. Pages 213-238 In: F. R. Haur and G. A. Lamberti (eds.), Methods in Stream Ecology. Academic Press, San Diego, California, USA.

Tank, J. L., and W. K. Dodds. 2003. Nutrient limitation of epilithic and epixylic biofilms in ten North American streams. Freshwater Biology 48: 1031-1049.

Tank, J. L., E. J. Rosi-Marshall, M. A. Baker, and R. O. Hall. 2008. Are rivers just big streams? A pulse method to quantify nitrogen demand in a large river. Ecology 89: 2935-2945.

Vannote, R. L., G. W. Minshall, K. W. Cummins, J. R. Sedell, and C. E. Cushing. 1980. The river continuum concept. Canadian Journal of Fisheries and Aquatic Sciences 37: 130-137.

Wetzel, R. G., and G. E. Likens. 2001. Composition and biomass of phytoplankton. Pages 139163 In: R. G. Wetzel and G. E. Likens (eds.), Limnological Analyses, $3^{\text {rd }}$. Edition. Springer New York, NY. 